\title{
Relative Contributions of Forest Vegetation, Land Cover, Topography and Climate in Explaining Fire Regime Patterns (1974-2005) in Peninsular Spain
}

\author{
Antonio Vázquez de la Cueva \\ Instituto Nacional de Investigación y Tecnología Agraria y Alimentaria, Forest Research Centre, CIFOR-INIA, \\ Ctra. A Coruña km 7,5, 28040 Madrid, Spain \\ Correspondence should be addressed to Antonio Vázquez de la Cueva, vazquez@inia.es
}

Received 14 August 2012; Accepted 5 September 2012

Academic Editors: D. Czeszczewik, D. Huber, and J. F. Negron

Copyright (C 2012 Antonio Vázquez de la Cueva. This is an open access article distributed under the Creative Commons Attribution License, which permits unrestricted use, distribution, and reproduction in any medium, provided the original work is properly cited.

\begin{abstract}
The relevance of forest fires as a major disturbance factor in vegetation composition, dynamics, and structure is increasing in several ecosystem types. In order to develop adaptation procedures and to strengthen the resilience under future altered fire regimes, it is important to gain a greater understanding of the factors involved in regional fire regimes. This paper evaluates the relative contributions of forest vegetation, land cover, topography, and climate in explaining the fire regime patterns. The analyses were performed independently for 15 territory types delimited according to potential vegetation criteria. Redundancy analysis was used to enable the simultaneous ordination of the response (fire regime) and the explanatory variables. The results reveal important differences among the 15 territories. The explained variance ranged from low to medium depending on the territory. However, for the five territories with greatest fire incidence, the variance explained was more than 39\%. The proportion of territory covered by forest (derived from land cover information) was found to be the most relevant variable. Unexpectedly, the type of forest vegetation (derived from forest inventory data) appears to have played, at least in this approach and for some territories, a secondary role in explaining the registered fire regime patterns.
\end{abstract}

\section{Introduction}

Forest fires are recurrent disturbances that can be characterized by their regime, that is, the type of fire history registered in a defined area for a given time period $[1,2]$. A fire regime is determined by a large number of factors: the presence of ignition sources, topography, prevention, and extinction efficiency; existence of climatic conditions which favour the spread of fire; the amount, type, and arrangement of fuels at several spatial scales $[3,4]$. A fire regime can be characterized by means of a large variety of variables describing different aspects of fire incidence (e.g., $[5,6])$ ). Here I use the fire frequency and three variations of the fire rotation period using a $32 \mathrm{yr}$. time period.

In recent decades there has been a high incidence of forest fires in peninsular Spain, which have affected a large number of forest ecosystems and severely disturbed the dynamics and structure of the vegetation [7]. In addition, Mediterranean type ecosystems are among the most vulnerable to climatic change and will suffer severe consequences [8-10]. This is partially due to the expected increase in the recurrence of severe drought and to the warmer and more arid conditions anticipated as a result of higher temperatures. These conditions could lead to increased fire frequency and to a greater proportion of large fires, resulting in an altered fire regime.

The relative roles of fuels versus weather components in explaining fire regimes are an important aspect of fire ecology (e.g., [11-13]). In moderate weather situations, fuel load and its structure can explain the enormous differences in fire behaviour whereas these differences are not as pronounced in extreme weather conditions [14]. To address these issues, I elaborated and analyzed four sets of fuel-related and weather related factors. This involved the characterization of forest 
vegetation and land cover types in the case of fuel-related factors and in the case of weather related factors; a climatic and topographic characterization was performed. The group of variables related to the type of forest vegetation was derived from the second National Forest Inventory (IFN-2), which provides details of the forest vegetation characteristics from almost 90,000 permanent plots. The type of land cover was the second group of variables in the fuel-related component and was derived from the CORINE Land Cover European cartography (CLC-1). The weather component was covered by meteorological variables derived from data provided by the Spanish meteorological agency [15] along with a characterization of the topographic patterns of each sample unit.

The relative importance of each of these components will also be dependent on the ecosystem type. Previous studies have highlighted the importance of spatial patterns related to potential natural vegetation regions in the registered fire regime [16] as well as to gradients of potential forest productivity [17]. Therefore, I have performed the analyses independently for 15 types of territory, or ecozones, dividing peninsular Spain according to a potential natural vegetation classification.

The general objectives of this study are to characterize the fire regime in the 15 territories over a $32 \mathrm{yr}$. period and to evaluate the relative contributions of the four sets of explanatory variables in explaining the registered fire regime patterns. The starting hypothesis is that variables from the four sets will explain the fire regime pattern to different degrees in each of the territories. We can expect to find that territories with a large proportion of forest cover, dominated by coniferous species in territories with strong topographic patterns and a high yearly variability in precipitation, will suffer the greatest fire occurrence.

The specific objectives of the analyses performed are as follows: (1) to provide a characterization of the recent fire regime registered in the 15 territories; (2) to identify by means of a multivariate ordination which of the groups of variables, and which of the variables within each group, have been more relevant in each of the territories; (3) to provide a graphical synthesis of the relationship between fire regime and environmental variables using ordination biplots.

\section{Material and Methods}

2.1. Forest Fire Data. The forest fire data used are those recorded in peninsular Spain during the period 1974-2005 (32 yrs.) and were supplied by the Spanish forest administration. Each fire was referenced to the $10 \times 10 \mathrm{~km}$ grid unit in which it originated. Reliable data were not available for several provinces (Spain is divided into 50 such administrative divisions) and years, so these were excluded from the analysis (e.g., Álava and Navarra in northern Spain). The fires considered in this study are only those which resulted in a burned forest area greater than 0.1 ha. I used 3,619 out of the 5,007 grid units defined for referencing forest fire location in peninsular Spain according to previous studies [17].

The fire regime over the $32 \mathrm{yr}$. period and for each sample unit $(10 \times 10 \mathrm{~km}$ grid units in most cases, except on borders, coasts, or meridian changes) was characterized in terms of fire frequency (number of fires registered in 10,000 ha of forest area, according to CLC-1, and year) and the fire rotation period (number of years required to burn an area equivalent to the reference forest surface). The rotation period was calculated independently for the total forest area (the sum of wooded and nonwooded), the wooded forest area (which has a relatively closed canopy of tall trees) and the nonwooded forest area (characterized by scattered trees or dominated by sclerophyllic Mediterranean trees and/or shrubs).

2.2. Delimitation of the Territory. The map of potential natural vegetation series [18] was used to classify each $10 \times 10 \mathrm{~km}$ grid unit into one of the 15 territory types, or ecozones, defined. Table 1 presents several characteristics of the 15 territories, which are presented at the same spatial resolution as the forest fire data $(10 \times 10 \mathrm{~km})$ in Figure 1 . The territories 1,2, and 4 are clearly within the Eurosiberian Region while others (e.g., 3 and 5) could also be ascribed to the Mediterranean one because of the importance of the transition zone between regions and the generalizations performed. Within the typical Mediterranean region, the dominant trees in types 7 to 13 are sclerophyllic species, among which Quercus rotundifolia is prevalent. Type 7, on the Mediterranean coast also has a large proportion of Q. ilex. Q. rotundifolia areas, which cover most of the peninsula, are subdivided according to bioclimatic belts. I have identified a supra-Mediterranean belt (type 9), and a meso-Mediterranean belt in the north (type 8) as well as in the south (type 12). Other meso-Mediterranean territories are divided up according to the substrate: acidic in the west (type 10) and basic in the east (type 11). Finally, there is a thermo-Mediterranean belt (type 13). Q. suber (type 14) is dominant in several locations while type 15 areas are dominated by Q. coccifera.

Although conifers (mainly pine species) make up a high proportion of the current wooded forest area in the Mediterranean and Eurosiberian regions of Spain, most are considered subdominant within other vegetation units (at least in the classification used), forming secondary forests or being spread through afforestation. Hence, in most cases, they are not explicitly considered in the territorial division employed. In some cases they are aggregated with other vegetation types.

\subsection{Environmental Variables}

2.3.1. Forest Inventory. Data from the IFN-2 (conducted between 1985 and 1995) were used, although only those plots that were resampled in the IFN-3 (1995-2005) were taken into consideration. Tree species data was classified into three vegetation classes: conifers, sclerophyll (evergreen), and deciduous trees. The approach employed considers two types of variable for each forest vegetation type. The first of these is the number of plots in which each of the three classes is present, over the total number of plots sampled in each of the $10 \times 10 \mathrm{~km}$ grid units. The second variable is the basal area (BA) expressed in $\mathrm{m}^{2} /$ ha and calculated for each of the 
TABLE 1: Reference areas and fire regime parameters (fire frequency and rotation periods) in the 15 territories. We present the total area, the proportion of territory selected, the proportion of forest area, the number of $10 \times 10 \mathrm{~km}$ grid-units considered in each one and the fire regime variables as median values.

\begin{tabular}{|c|c|c|c|c|c|c|c|c|c|}
\hline \multirow{3}{*}{ Code } & \multirow{3}{*}{$\begin{array}{c}\text { Territory types } \\
\text { Main tree species (Abbreviation) }\end{array}$} & \multicolumn{4}{|c|}{ Areas of reference } & \multicolumn{4}{|c|}{ Fire regime (1974-2006) (median values) } \\
\hline & & \multirow{2}{*}{$\begin{array}{l}\text { Total } \\
\left(\mathrm{km}^{2}\right)\end{array}$} & \multicolumn{3}{|c|}{ Selected } & \multirow{2}{*}{$\begin{array}{l}\text { Frequency } \\
\text { Fires } 10^{3} \mathrm{ha}^{-1} \mathrm{yr}^{-1}\end{array}$} & \multicolumn{3}{|c|}{ Rotation period (years) } \\
\hline & & & $\%$ & Forest $(\%)$ & Grids $(n)$ & & Forest area & Wooded & Non wooded \\
\hline 1 & Pinus uncinata/abies alba [P. unc./A. al.] & 8,610 & 79 & 66 & 69 & 0.5 & 1,896 & 2,810 & 2,009 \\
\hline 2 & Fagus sylvatica [F. syl.] & 9,960 & 87 & 86 & 87 & 2.5 & 303 & 598 & 261 \\
\hline 3 & Juniperus thurifera [J. thu.] & 8,000 & 69 & 67 & 55 & 0.6 & 4,392 & 3,879 & 6,706 \\
\hline 4 & Quercus robur [Q. rob.] & 36,440 & 98 & 63 & 373 & 12.5 & 70 & 72 & 70 \\
\hline 5 & Q.pyrenaica [Q.pyr.] & 45,440 & 97 & 68 & 444 & 3.1 & 135 & 161 & 137 \\
\hline 6 & Q. faginea/Q. pubescens [Q. fag.] & 40,470 & 76 & 49 & 307 & 0.9 & 1,245 & 1,426 & 1,502 \\
\hline 7 & Q. ilex/Q. rotundifolia [Q. ile.] & 22,330 & 96 & 50 & 214 & 2.4 & 168 & 150 & 246 \\
\hline 8 & Q. rot. (meso/north) [Q. rot. ms./N.] & 57,470 & 67 & 38 & 372 & 1.5 & 700 & 811 & 784 \\
\hline 9 & Q. rot. (supra) [Q. rot. su.] & 34,760 & 69 & 40 & 239 & 0.8 & 1,343 & 1,477 & 1,703 \\
\hline 10 & Q. rot. (meso/acid) [Q. rot. ms./Ac.] & 69,100 & 82 & 56 & 551 & 0.8 & 508 & 618 & 552 \\
\hline 11 & Q. rot. (meso/basic) [Q. rot. ms./Ba.] & 45,700 & 48 & 18 & 218 & 1.2 & 953 & 1016 & 1,517 \\
\hline 12 & Q. rot. (meso/south) [Q. rot. ms./S.] & 27,910 & 68 & 18 & 189 & 2.2 & 642 & 643 & 679 \\
\hline 13 & Q. rot. (thermo) [Q. rot. th.] & 23,860 & 60 & 22 & 146 & 3.0 & 222 & 166 & 395 \\
\hline 14 & Q. suber [Q.sub.] & 15,180 & 93 & 65 & 143 & 1.5 & 206 & 195 & 191 \\
\hline 15 & Q. coccifera [Q. coc.] & 34,540 & 61 & 31 & 212 & 1.0 & 1,831 & 955 & 2,623 \\
\hline
\end{tabular}

four diametric classes measured in the field as well as for each of the three types of tree. The total BA is then computed for each plot. Finally, I calculated the mean value for each type of tree and each $10 \times 10 \mathrm{~km}$ grid unit (maximum of 100 plots in each grid unit of normal size). The codes and definitions of the six IFN-2-derived variables finally used in the analyses are presented in Table 2 .

2.3.2. Land Cover Data. The characterization of the land cover in each $10 \times 10 \mathrm{~km}$ grid unit was based on the CORINE (CLC-1) cartography. For peninsular Spain, Landsat 5 TM images from summer 1986 were mainly used. Data used were obtained from the European Environmental Agency [19]. Using the original types of cover identified in the CLC-1 legend as a starting point, 5 categories of forest classes were identified. For three of the categories defined I decided to keep the original legend (wooded forest). These are (3.1.1) "Broad-leaved forest," (3.1.2) "Coniferous forest," and (3.1.3) "Mixed forest". In the other two categories I combined several types in order to define what I consider the nonwooded forest area. The first of these is the "agro-forestry category", which integrates two of the classes defined in the original legend, namely (2.4.3) "Land principally occupied by agriculture, with significant areas of natural vegetation" and (2.4.4) "Agro-forestry areas". The other nonwooded forest class, which I have termed "shrubland area", is a combination of seven of the original classes including "natural grasslands" (3.2.1) and "sclerophyllous vegetation" (3.2.3). The variables used were calculated for each $10 \times 10 \mathrm{~km}$ grid unit and are defined in Table 2.

2.3.3. Topography. In order to characterize the topographic characteristics of each of the sampling units $(10 \times 10 \mathrm{~km}$ grids), we used a Digital Terrain Model (DTM) with $100 \mathrm{~m}$ spatial resolution. I determined the average values, the variability and the ranges of elevation and slope. These variables are defined in Table 2.

2.3.4. Meteorological Data. The meteorological variables used are derived from the output of the regional climate model PROMES-UCM, developed by the Spanish meteorological agency [15]. I used data from the 1961-1990 period. The initial data were obtained with a spatial resolution of $0.5 \times 0.5$ degrees covering peninsular Spain and was composed of daily data for precipitation, mean temperature (at 2 meters), maximum temperature (at 2 meters), mean wind speed (at $10 \mathrm{~m}$ ), and maximum wind speed (at $10 \mathrm{~m}$ ). I calculated 6 variables for each grid unit (see Table 2).

2.4. Analysis Procedures. The statistical procedure was based on redundancy analysis (RDA) [20], a type of canonical ordination. In these analyses the canonical axes obtained in the ordination are a linear combination of the explanatory variables. Fire frequency along with the three fire rotation periods calculated were used as response variables. The explanatory variables initially used in all cases were the 26 environmental variables characterizing the type of forest vegetation (6), the land cover (8), the topography (6), and the climate (6) (Table 2). I developed a hybrid variant in which the axes 1 and 2 are canonical and the axes 3 and 4 are free. The relationship between the eigenvalues of these two types of axes can indicate the relationship between the response and the explanatory matrices. Additionally, the forward selection method was used to select and rank the explanatory variables according to their importance in explaining the fire regime patterns for each of the 15 territories [20]. 


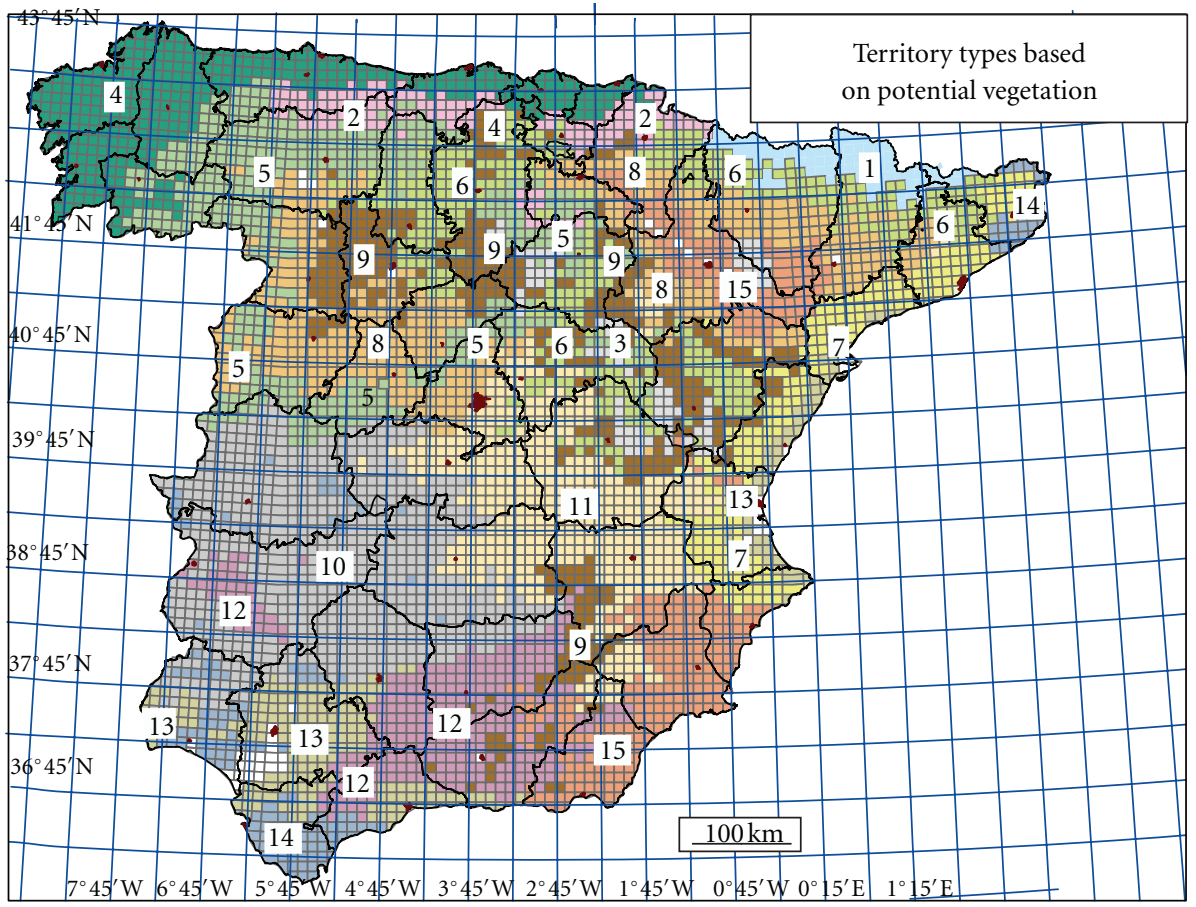

Type of territory

\begin{tabular}{|l} 
(1) P.unc./A.al. \\
(2) F.syl. \\
(3) J.thu. \\
(4) Q.rob. \\
(5) Q.pyr. \\
(6) Q.fag. \\
(7) Q.ile. \\
(8) Q.rot. Ms./N. \\
(9) Q.rot su.
\end{tabular}

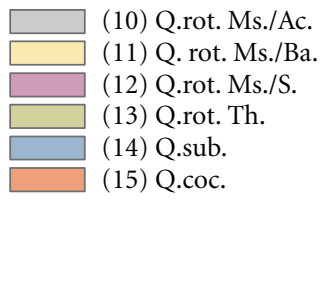

Figure 1: Territories delimited in peninsular Spain using potential vegetation criteria at the $10 \times 10 \mathrm{~km}$ grid unit spatial resolution used in the analyses. Administrative limits (provinces) and main urban areas (in red) are also displayed (see Table 1 and Section 2.2 for more information).

This variable selection was validated through Monte Carlo permutation tests.

I performed a standardised RDA, based on a correlation matrix. Fire regime variables were transformed by logarithmic function and standardised. Response variables, which were also associated with different units, had to be transformed and standardized (with mean 1 and variance 0 ). Correlation biplots, which focus on variables instead of samples, were employed. Hence, the ordination diagram obtained allows the correlation between the fire regime and the selected (best ranked) explanatory variables to be easily visualized. Multivariate analyses were performed using CANOCO 4.5 and the biplots were drawn with Canodraw [21]. In the biplots, each vector points towards the maximum variation in the variable values. The length of the vectors indicates the strength of the correlation. Vectors pointing in the same direction indicate correlation between the two. Canonical axes (ranging from -1 to +1 ) are constrained in these analyses to be a linear combination of the explanatory variables. Each biplot displays the four response variables and the most statistically significant explanatory variables.

\section{Results}

3.1. Recent Fire Regime in Peninsular Spain. During the $32 \mathrm{yr}$. period from 1974 to 2005 at least 344,000 fires ( $\geq 0.1 \mathrm{ha}$ ) were registered in peninsular Spain. These fires affected approximately $6 \times 10^{6}$ ha. The fire regime variables reveal large variability among the 15 territories defined. Median values of fire frequency for each territory ranged from 0.5 in type 1 to extreme values of 12.5 in type 4 . The highest median value for the rotation period was registered in territory 3 while the shortest median value $(70$ yrs.) was registered in territory 4 (Table 1). Between these two extremes, the figures for other territories vary considerably. This high level of spatial variability in the fire regime is reflected in the maps presented in Figure 2. It can be appreciated in Figure 2(a) that fire frequency is particularly high in several regions of peninsular Spain, especially in the northwest. The incidence of fires was very high (fire frequency $\geq 5$ fires $10,000 \mathrm{ha}^{-1} \mathrm{yr}^{-1}$ ) in $23 \%$ of the grid units although these fires made up $77 \%$ of the total number of fires. Over the 32 years considered, fire rotation periods of less than 100 
TABLE 2: Explanatory variables, grouped in the four sets, code, units, description, and the number of times each one has been chosen in the RDA analyses performed for the 15 territories.

\begin{tabular}{|c|c|c|c|c|c|}
\hline \multicolumn{4}{|c|}{ Environmental variables } & \multicolumn{2}{|c|}{ Times selected } \\
\hline Set & Code & Units & Description & In first position & In the model \\
\hline \multicolumn{6}{|c|}{ (1) Type of forest vegetation } \\
\hline \multirow{6}{*}{ IFN-2 } & Conif_\# & $\%$ & Plots with conifers versus total number of plots & 0 & 3 \\
\hline & Conif_BA & $\%$ & Basal area of conifers versus total basal area & 0 & 0 \\
\hline & Scler_\# & $\%$ & Plots with sclerophyll versus total number of plots & 0 & 0 \\
\hline & Scler_BA & $\%$ & Basal area of sclerophyll versus total basal area & 0 & 3 \\
\hline & Decid_\# & $\%$ & Plots with deciduous versus total number of plots & 0 & 1 \\
\hline & Decid_BA & $\%$ & Basal area of deciduous versus total basal area & 0 & 0 \\
\hline \multirow{9}{*}{ CLC-1 } & (2) Type of 1 & & & & \\
\hline & For_area & $\%$ & Forest area versus total area & 7 & 12 \\
\hline & Wd_For & $\%$ & Wooded forest versus forest area & 1 & 6 \\
\hline & Nwd_For & $\%$ & Non wooded forest versus forest area & 0 & 0 \\
\hline & Dec_Wd & $\%$ & Deciduous forest versus wooded forest area & 0 & 3 \\
\hline & Con_Wd & $\%$ & Coniferous forest versus wooded forest area & 0 & 4 \\
\hline & Mix_Wd & $\%$ & Mixed forest versus wooded forest area & 0 & 0 \\
\hline & Agr_Nwd & $\%$ & Agroforest area versus non wooded forest area & 0 & 1 \\
\hline & Shr_Nwd & $\%$ & Shrubland area versus non wooded forest area & 1 & 1 \\
\hline \multicolumn{6}{|c|}{ (3) Topographic characterization } \\
\hline \multirow{6}{*}{ DTM } & Elev_ran & $\mathrm{m}$ & Range of elevations & 0 & 3 \\
\hline & Elev_avg & $\mathrm{m}$ & Average of elevations & 3 & 10 \\
\hline & Elev_dev & $\mathrm{m}$ & Standard deviation of elevations & 0 & 4 \\
\hline & Slo_ran & $\%$ & Range of slopes & 0 & 2 \\
\hline & Slo_avg & $\%$ & Average of slopes & 0 & 2 \\
\hline & Slo_dev & $\%$ & Standard deviation of slopes & 0 & 1 \\
\hline \multicolumn{6}{|c|}{ (4) Climatic characterization } \\
\hline \multirow{6}{*}{ Aemet } & Prec_avg & $\mathrm{mm}$ & Mean precipitation for $1961-1990$ & 2 & 5 \\
\hline & Prec_var & $\mathrm{mm}$ & Variance for the yearly precipitation & 1 & 4 \\
\hline & Temp_avg & ${ }^{\circ} \mathrm{C}$ & Mean temperature (at 2 meters) & 0 & 3 \\
\hline & Temp_mx & ${ }^{\circ} \mathrm{C}$ & Mean of the yearly maximum temperatures & 0 & 2 \\
\hline & Wind_avg & $\mathrm{m} / \mathrm{s}$ & Mean wind speed (at $10 \mathrm{~m})$ & 0 & 5 \\
\hline & Wind_mx & $\mathrm{m} / \mathrm{s}$ & Mean of maximum yearly wind speed & 0 & 1 \\
\hline
\end{tabular}

years were registered in 22\% of the grids (Figure 2(b)). Rotations of less than 20 years, which would imply fires involving mainly shrubby vegetation or nonmature forest, were registered in several regions, illustrating the high recurrence of fires in certain landscapes. When only the wooded forest areas are considered in the calculations (not shown), the rotation period is even shorter.

3.2. Ordination Patterns and Explanatory Variables. Eigenvalues for the two first canonical axes, those formed as a linear combination of the explanatory variables, ranged from 0.14 (for types 10 and 11) to greater or equal to 0.45 (types 4 and 2). For the overall analysis, most of the explained variance was in the first axis (Table 3 ). The Monte Carlo permutation test $(n=999)$ indicated that the canonical axes were statistically significant $(P<0.01)$ in the 15 analyses. The two free axes ( 3 and 4 ), representing the variance not explained by the canonical axes, presented eigenvalues from 0.49 to 0.76 . The ratios between the canonical and the free axes differed considerably. Hence, in the case of territories 10 and 11, which had the lowest ratios (19\%), the canonical axes were of little relevance in explaining fire regime patterns. However, in the case of types 2, 4, and 5, for example, the ratios suggest that the canonical axes can successfully explain the fire regime patterns (Table 3 ).

The explanatory variables selected for each analysis (from the 26 variables considered initially) were those which contributed to the regression model $\geq 1 \%$ and which were statistically significant according to the Monte Carlo permutation tests. The number of times each variable was selected in the first position or within the model is shown in Table 2, while the ranking of the explanatory variables for the 15 ordinations is shown in Table 3 . The proportion of forest area (For_are) was particularly relevant in 12 of the 15 models; 7 times in the first position (Tables 2 and 3). The variables belonging to this group (land cover) were generally the most relevant. The next most relevant variable was the average elevation of the grid unit (Elev_avg), which was 

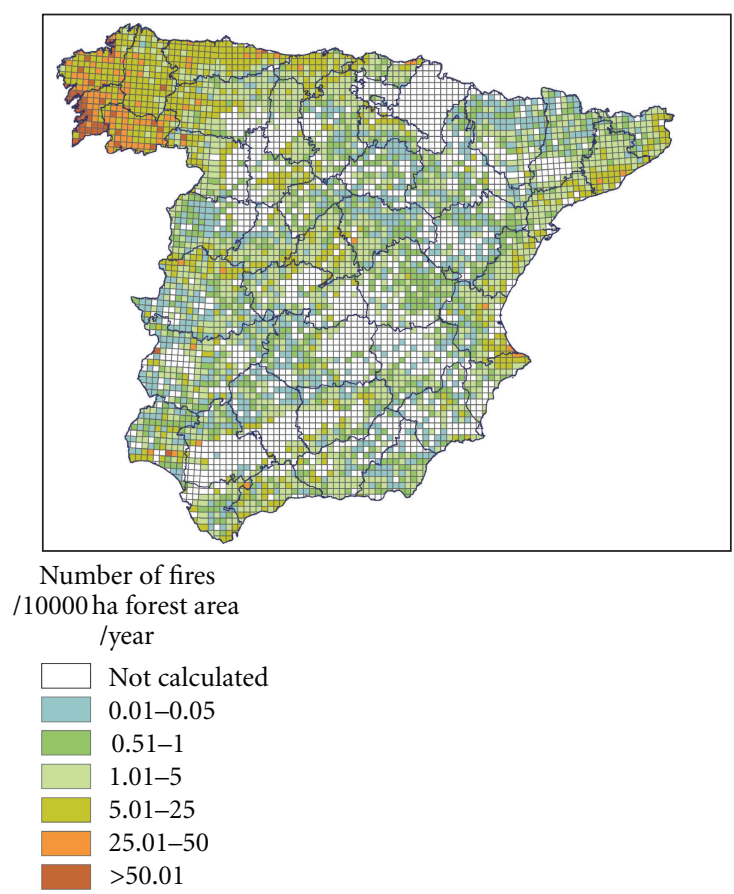

(a) Fire frequency 1974-2005

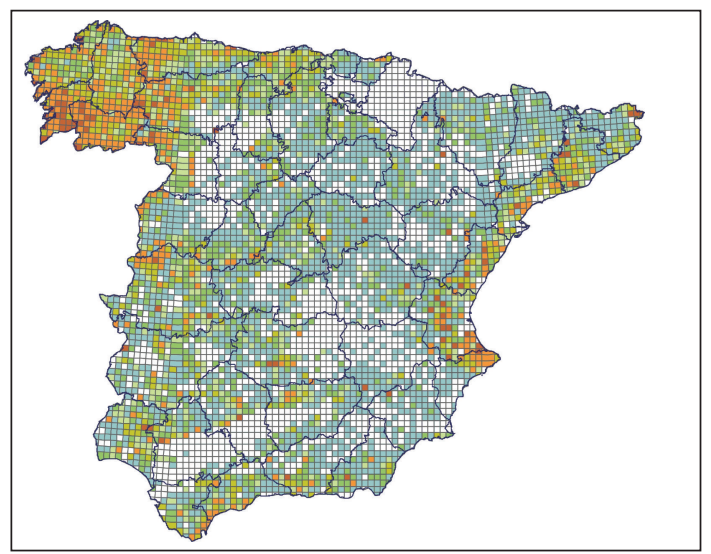

Number of years to burn

an area equal to forest area
Not calculated
$0.01-20$
$20.01-50.0$
$50-100$
$100.01-200$
$200.01-500$
$>500.01$

(b) Rotation period of forest area 1974-2005

Figure 2: Maps displaying the fire frequency (a) and the fire rotation period (b) calculated on a $10 \times 10 \mathrm{~km}$ grid unit base and the administrative limits (provinces).

selected in 10 models, 3 times in the first position and 4 times in the second position. Other topographic variables were selected in the rest of the ordinations. As regards the group of climatic variables, those related to precipitation (mean value and the yearly variability) occupied the first position in three of the ordinations. Finally, the variables derived from the forest inventory were found to be of little relevance in this approach. Only three of the six variables from this group were selected and only in a few of the analyses. Moreover, none of these variables occupied the first position in any of the analyses (Tables 2 and 3).

3.3. Graphical Synthesis: Correlation Biplots. All the abovementioned information together with the response variable ordination is displayed graphically in the form of biplots (Figure 3). In these biplots, the response variables (black vectors) create a gradient characterized by higher fire frequencies (and thus shorter rotation periods), which point in one direction, and longer rotation periods (and thus lower frequencies), which point in another direction. The three response variables related to the rotation periods (calculated for the forest area, for the wooded and for the nonwooded areas) displayed similar behaviour in general, as indicated by the directions of the vectors representing these variables. The selected explanatory variables (those presented in Table 3 ) are represented by red vectors.

\section{Discussion}

Although a large number of factors are involved in fire regimes, many of which are not covered sufficiently in this approach, the environmental variables used were found to have moderate explanatory power. The results reveal that in almost half the territories, more than $25 \%$ of the variance was explained by the environmental variables considered. Furthermore, in the five types of territory with high fire incidence (median frequencies above 2.4, as in types 2, $4,5,7$, and 13), the variance was greater than $39 \%$. In these territories, the median values for the rotation period ranged from 70 to 300 years. In addition, as suggested in the initial hypothesis, the importance of each group of variables changed according to the type of territory considered.

4.1. Fuel Components: Type of Forest Vegetation and Type of Land Cover. Variables related to the spatial component of fuels were found to be particularly relevant, especially the proportion of forest area. This variable, derived from the CLC-1, was selected in $80 \%$ of the models and occupied the first position in almost $50 \%$ of them. However, the variables derived from the forest inventory were found to be of little relevance, at least in this approach. Contrary to expectations, the inventory variables were poorly related to the fire regime variables. They also tended to be more related to rotation periods than to frequencies (e.g., type 13). It was expected that differences in flammability as well as in stand structure between conifers, deciduous, and sclerophyllic species [2] would be reflected in the models through the selection of determined variables. Furthermore, the expected pattern was reported at regional scale by González et al. [22], also using IFN-2 data. These authors developed a fire probability model for northeast Spain in which a change from pure 

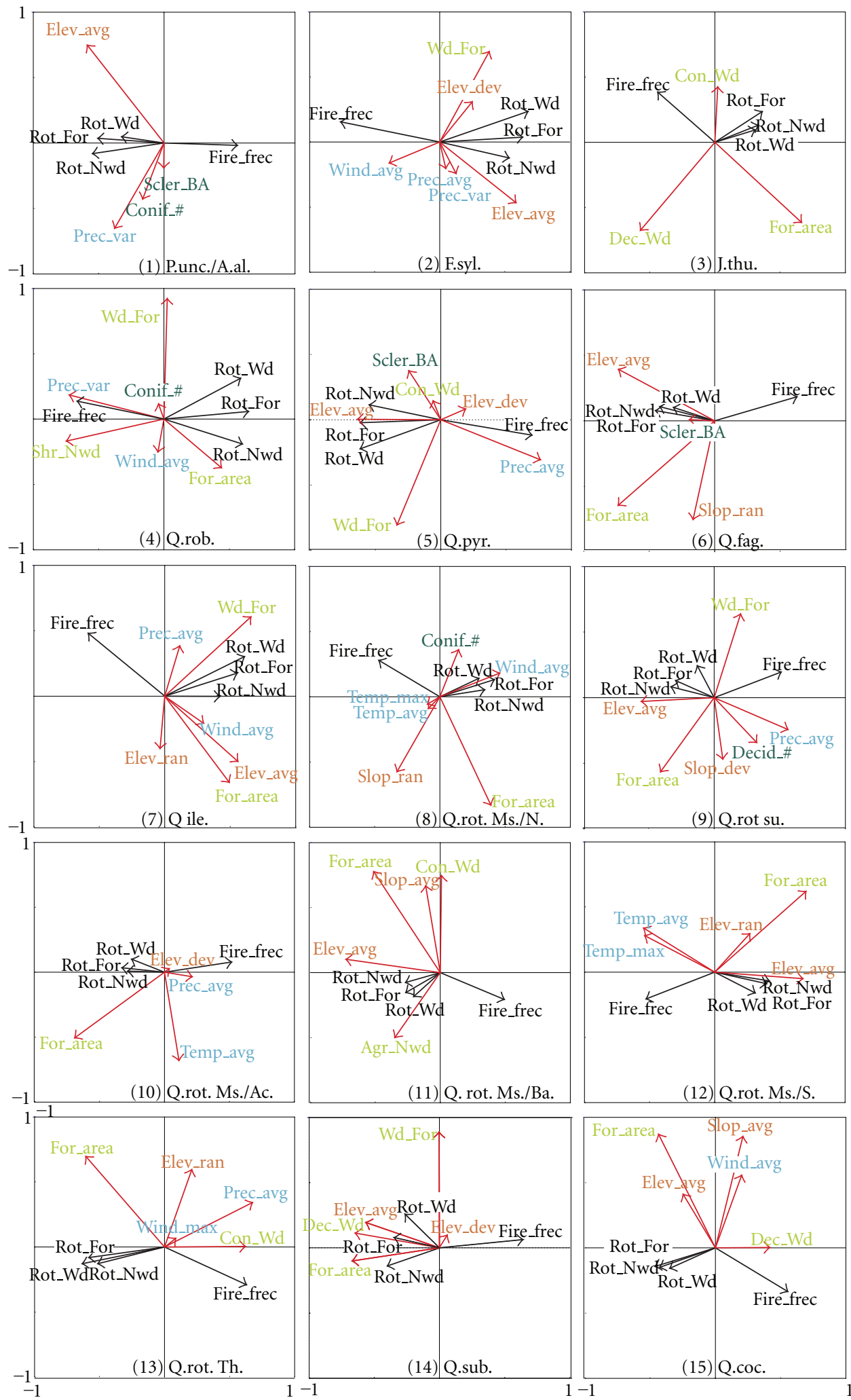

FIGURE 3: Correlation biplots based on RDA performed between the fire regime variables (response data set represented by black vectors) and the four groups of explanatory variables (red vectors with each group in a different colour) for the 15 territories analysed (see Table 2). Each vector points in the direction of maximum variation of the variable values. The length of the vectors indicates the correlation strength. Vectors pointing in the same direction indicate a correlation between them. Each biplot displays the best ranked and significant explanatory variables. 


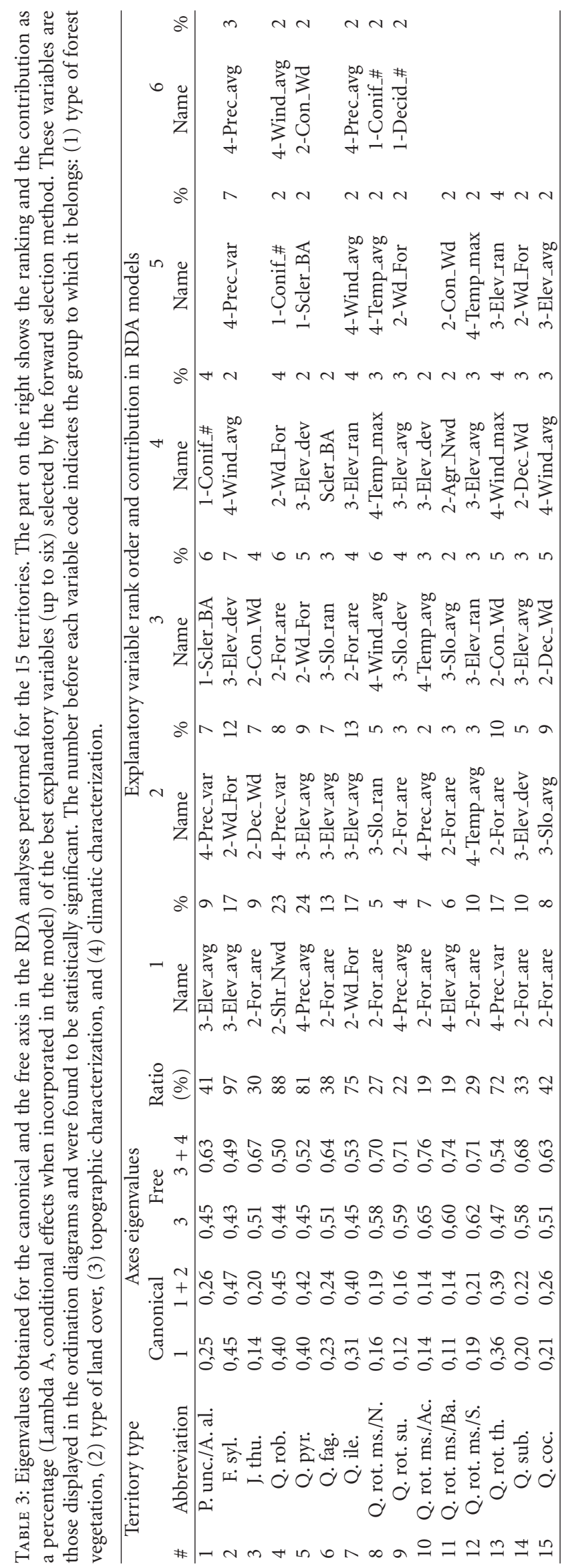


hardwood stands to pure coniferous stands would increase the probability of fire by 5.8 times. Fernandes et al. [23] also found differences in wildfire severity between stands of Pinus pinaster and other stands in the mountains of northwestern Portugal due to the patterns of fire propagation in combination with the fuel effect implicit in the change of cover type. In my opinion, the low relevance of IFN-2 variables in the analyses might be explained by differences in the scale (we used mean values for $10 \times 10 \mathrm{~km}$ units) as well as in the stand characteristics selected. Other structural characteristics such as stand density or tree size were not considered as they had been considered in previous trials.

In addition, the IFN-2 is a valuable tool in forestry planning and management [24] although the sampling carried out in these inventories might be considered biased if "forest area" is interpreted in a wider sense, including both wooded and nonwooded forest vegetation. This bias becomes clearer if we consider that according to the IFN-2 data, conifers were present in $50 \%$ of the plots, sclerophyll species in only $27 \%$, and deciduous in $23 \%$. These figures do not tie in with information on the distribution of vegetation types from other sources such as the CLC-1 data. One possible explanation for this is that IFN's initially focused on wood stocks. Therefore, conifer forests are sampled systematically while other open forests are hardly sampled at all. Finally, some relevant variables such as the proportion of shrublands (the more relevant in territory 4) are not available in IFN-2 because the plots were performed mostly in wooded places.

The proportion of forest surface (derived from CLC-1 data) was found to be the most relevant predictor variable. Landscape patterns can determine the spread of disturbances such as fires $[25,26]$. This could be related to the fact that under normal conditions a threshold exists below which a landscape becomes essentially fireproof. Krawchuk et al. [13] in an analysis of the global distribution of fires using climate, vegetation, and ignition variables found that the net primary productivity, used as a proxy for fuel availability, was more closely related to fire distribution than any other predictor variable. In spite of the differences in scale this finding is supported by the results. However, in the case of our territories, the relationships are not always direct. Our results show that in several territories (e.g., 8 and 13) a large proportion of forest area is associated with lower fire incidence. This could be partially explained by regional patterns of forest and fire ignition distribution. Moreira et al. [27] in an analysis of regional variations in the susceptibility of different land cover types to wildfires in Portugal found that shrublands were the most fire-prone type of land cover. These patterns are similar to those of type 8 , in which the proportion of shrubland was the first selected variable. This vegetation type is also prevalent in large areas of Portugal, especially in the north, where fire incidence is higher. In another study conducted in Portugal, Nunes et al. [28] found that in the case of small fires, shrubland was often the predominant type of land cover burned whereas in the case of very large fires, conifers (particularly P. pinaster) were more often affected. In a wildfire modelling approach, again focusing on Portugal, Catry et al. [29] found that land cover type played a determinant role; on the one hand, different types of land cover present different fuel characteristics (type, load, moisture, flammability) and on the other, certain land uses are associated with a greater use of fire (e.g., traditional burning).

4.2. Weather Components: Climatic and Topographic Characterization. The average elevation value was found to be the most relevant topographic variable and was selected in $66 \%$ of cases, suggesting the existence of a clear gradient. The significance of the elevation variable in the present study should be interpreted as a regional pattern within each of the territories related to the presence of highlands (mountains) versus lowlands. Elevation was also found to be a determinant factor in the above-mentioned wildfire ignition risk model for Portugal [29]. This positive relationship between wildfire ignition and elevation may be due to human activities in mountain regions, such as pastoral activities, which are known to have affected fire regimes in some areas. Lightning-caused ignition also seems to be more common at higher elevations $[7,30]$ and although few in proportion, they are very relevant in certain areas, especially in the east of the Iberian Peninsula.

A pattern of fire incidence was detected at national scale [17] in which the underlying factor was identified as forest productivity. This implies that the biomass accumulation associated with the level of precipitation controls to a large extent the incidence of fire. It is assumed that climatic conditions conducive to the spread of fire frequently exist. These patterns can be clearly identified in several of the territory types (e.g., 5 and 9), in which the mean yearly precipitation occupies the first position. In other territories, precipitation variability was the most relevant factor. In any case, drought periods are not explicitly reflected in the meteorological data used. The relatively weak influence of temperatures and winds may also be explained by the fact that they are mean values for the whole period and therefore the extreme events are not taken into account.

4.3. Patterns of Relationships. Although the vegetation classification used in this study considers pine species to be subdominant within other vegetation units, frequently spread through afforestation, it is clear they make up a substantial proportion of the trees in Spanish forests. Some of the largest fires registered in Spain have occurred on the Mediterranean coast and many of these were caused by lightning, as happened in 1994, [7]. These fires mainly affected $P$. halepensis reforestations or areas invaded by the species where cultivation has been abandoned (e.g., $[31,32]$ ). In this area (type 7) the pattern obtained shows that a higher proportion of wooded forest (according to the CLC-1) was correlated with longer rotation periods. This was also the case in other territories such as type 8. In the latter area there are a number of managed $P$. sylvestris forests which have had a relatively low fire incidence over recent decades. In contrast, the large proportion of conifers in territory 13 (again according to the CLC-1) was correlated with shorter rotation periods.

It is important to note that the sampling unit is $10 \times 10 \mathrm{~km}$ and that these areas frequently exhibit a large 
variability in fire incidence, especially in mountain regions. This factor might explain the patterns detected in the arid type 15 territories in which a large proportion of deciduous species is related to a higher incidence and shorter rotation periods. Productivity patterns linked to the deciduous trees may also provide a partial explanation. Although I have not considered temporal trends in fire size in this study, it is important to remember that their relative importance is also increasing [7] as is the probability of extreme weather conditions in which fire suppression is much more difficult. The analyses performed point to the amount of forest area as the main driver of fire occurrence while variables related to the type of forest are secondary, though relevant in some of the territories. These factors highlight the need to place more emphasis on fuel management, the only direct aspect in which man plays a role. González et al. [22] and Fernandes et al. [23] suggest the reduction of stand density and the expansion of broadleaved deciduous or evergreen forest as a means to create more fire-resilient ecosystems and landscapes. Accordingly, fuel management and therefore forest management strategies should be primarily designed to mitigate the spread of fire and the adverse effects on the landscape. Strategies such as these will help towards attaining the sustainable coexistence of forests and fires under the altered fire regimes expected in the near future.

\section{Acknowledgment}

The author thanks the Spanish forest administration for allowing him access to the fire data and also the Agencia Española de Meteorología (Aemet) for the Regional Climate Model. The European Environmental Agency provided the CORINE data. Thanks also to MLM, CPL, and SSF for their continuous support. This work is dedicated to José M. Vázquez for introducing the author to the world of forests and fires. This work was made possible in part thanks to funds provided by the Spanish "Ministerio de Educación y Ciencia" through a "Ramón y Cajal" contract and the Caresoil-CM (P2009/AMB-1648) network.

\section{References}

[1] F. W. Davis and D. A. Burrows, "Spatial simulation of fire regime in Mediterranean climate landscapes," in The Role of Fire in Mediterranean-Type Ecosystems, J. M. Moreno and W. C. Oechel, Eds., pp. 117-139, Springer, NewYork, NY, USA, 1994.

[2] W. J. Bond and B. W. Van Wilgen, Why and How Do Ecosystems Burn? Fire and Plants, Chapman \& Hall, London, UK, 1996.

[3] R. C. Rothermel, "How to predict the spread and intensity of fires?” Tech. Rep. INT-143, US Department of Agriculture, Forest Service, Ogden, Utah, USA, 1983.

[4] L. Trabaud, "Wildland fire cycles and history in central southern France," in Proceedings of the 1th International Conference on Forest Fire Research, pp. 545-556, Coimbra, Portugal, November 1994.

[5] E. A. Johnson, "Fire and vegetation dynamics: studies from the North American boreal forest," Fire and Vegetation Dynamics, 1992.
[6] R. Díaz-Delgado, F. Lloret, and X. Pons, "Spatial patterns of fire occurrence in Catalonia, NE, Spain," Landscape Ecology, vol. 19, no. 7, pp. 731-745, 2005.

[7] J. M. Moreno, A. Vázquez, and R. Vélez, “1998Recent history of forest fires in Spain," in Large Forest Fires, J. M. Moreno, Ed., pp. 159-185, Backhuys, Leiden, The Netherlands.

[8] J. Piñol, J. Terradas, and F. Lloret, "Climate warming, wildfire hazard, and wildfire occurrence in coastal eastern Spain," Climatic Change, vol. 38, no. 3, pp. 345-357, 1998.

[9] IPCC Europe, Climate Change 2007: Impacts, Adaptation and Vulnerability. Contribution of WG II to the 4th Assessment Report of the IPCC, Cambridge University Press, 2007.

[10] F. Lloret, J. Peñuelas, P. Prieto, L. Llorens, and M. Estiarte, "Plant community changes induced by experimental climate change: seedling and adult species composition," Perspectives in Plant Ecology, Evolution and Systematics, vol. 11, no. 1, pp. 53-63, 2009.

[11] W. C. Bessie and E. A. Johnson, "The relative importance of fuels and weather on fire behavior in subalpine forests," Ecology, vol. 76, no. 3, pp. 747-762, 1995.

[12] C. Hély, M. Flannigan, Y. Bergeron, and D. McRae, "Role of vegetation and weather on fire behavior in the Canadian mixedwood boreal forest using two fire behavior prediction systems," Canadian Journal of Forest Research, vol. 31, no. 3, pp. 430-441, 2001.

[13] M. A. Krawchuk, M. A. Moritz, M. A. Parisien, J. Van Dorn, and K. Hayhoe, "Global pyrogeography: the current and future distribution of wildfire," PLoS ONE, vol. 4, no. 4, Article ID e5102, 2009.

[14] M. A. Moritz, "Analyzing extreme disturbance events: fire in Los Padres National Forest," Ecological Applications, vol. 7, no. 4, pp. 1252-1262, 1997.

[15] M. Brunet, M. J. Casado, M. de Castro et al., Generación de Escenarios Regionalizados de Cambio Climático Para España, Aemet, Ministerio de Medio Ambiente, 2007.

[16] A. Vázquez, B. Pérez, F. Fernández-González, and J. M. Moreno, "Recent fire regime characteristics and potential natural vegetation relationships in Spain," Journal of Vegetation Science, vol. 13, no. 5, pp. 663-676, 2002.

[17] A. V. de La Cueva, J. M. G. Del Barrio, M. O. Quero, and O. S. Palomares, "Recent fire regime in peninsular Spain in relation to forest potential productivity and population density," International Journal of Wildland Fire, vol. 15, no. 3, pp. 397-405, 2006.

[18] S. Rivas-Martínez, Mapa de Las Series de Vegetación de España (1:400000), Ministerio de Agricultura, Pesca y Alimentación, Instituto Nacional Para la Conservación de la Naturaleza, Madrid, Spain, 1987.

[19] NATLAN, CORINE Land Cover 250 m. European Environment Agency, 2000.

[20] C. J. F. Ter Braak, "Canonical community ordination. Part I: basic theory and linear methods," Ecoscience, vol. 1, no. 2, pp. 127-140, 1994.

[21] C. J. F. Ter Braak and P. Smilauer, CANOCO Reference Manual and CanoDraw for Windows. USer's Guide: Software for Canonical Community Ordination (V. 4.5), Microcomputer Power, Ithaca, NY, USA.

[22] J. R. González, M. Palahí, A. Trasobares, and T. Pukkala, “A fire probability model for forest stands in Catalonia (North-East Spain)," Annals of Forest Science, vol. 63, no. 2, pp. 169-176, 2006.

[23] P. M. Fernandes, A. Luz, and C. Loureiro, "Changes in wildfire severity from maritime pine woodland to contiguous forest 
types in the mountains of northwestern Portugal," Forest Ecology and Management, vol. 260, no. 5, pp. 883-892, 2010.

[24] R. Vallejo and J. A. Villanueva, "El banco de datos de la naturaleza," in El Inventario Forestal Nacional. Elemento CLave Para la Gestión Forestal Sostenible, F. Bravo, M. del Río, and C. del Peso, Eds., Fundación General de la Universidad de Valladolid, Valladolid, Spain, 2002.

[25] R. H. Gardner, B. T. Milne, M. G. Turnei, and R. V. O’Neill, "Neutral models for the analysis of broad-scale landscape pattern," Landscape Ecology, vol. 1, no. 1, pp. 19-28, 1987.

[26] M. G. Turner, R. H. Gardner, V. H. Dale, and R. V. O’Neill, "Predicting the spread of disturbance across heterogeneous landscapes," Oikos, vol. 55, no. 1, pp. 121-129, 1989.

[27] F. Moreira, P. Vaz, F. Catry, and J. S. Silva, "Regional variations in wildfire susceptibility of land-cover types in Portugal: implications for landscape management to minimize fire hazard," International Journal of Wildland Fire, vol. 18, no. 5, pp. 563-574, 2009.

[28] M. C. S. Nunes, M. J. Vasconcelos, J. M. C. Pereira, N. Dasgupta, R. J. Alldredge, and F. C. Rego, "Land cover type and fire in Portugal: do fires burn land cover selectively?" Landscape Ecology, vol. 20, pp. 661-673, 2005.

[29] F. X. Catry, F. C. Rego, F. L. Bação, and F. Moreira, "Modeling and mapping wildfire ignition risk in Portugal," International Journal of Wildland Fire, vol. 18, no. 8, pp. 921-931, 2009.

[30] R. A. Minnich, E. F. Vizcaino, J. Sosa-Ramirez, and Yue-Hong Chou, "Lightning detection rates and wildland fire in the mountains of northern Baja California, Mexico," Atmosfera, vol. 6, no. 4, pp. 235-253, 1993.

[31] D. Moya, J. M. Espelta, I. Verkaik, F. López-Serrano, and J. De Las Heras, "Tree density and site quality influence on Pinus halepensis Mill. reproductive characteristics after large fires," Annals of Forest Science, vol. 64, no. 6, pp. 649-656, 2007.

[32] B. Prévosto, Y. Monnier, C. Ripert, and C. Fernandez, "Diversification of Pinus halepensis forests by sowing Quercus ilex and Quercus pubescens acorns: testing the effects of different vegetation and soil treatments," European Journal of Forest Research, vol. 130, no. 1, pp. 67-76, 2011. 

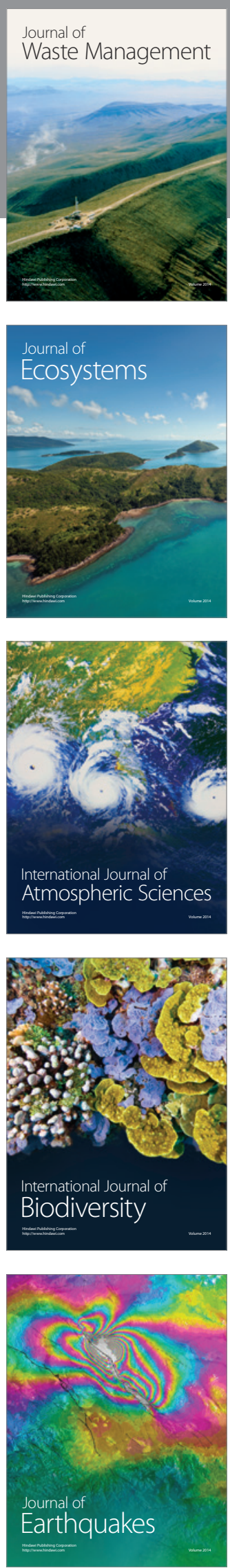
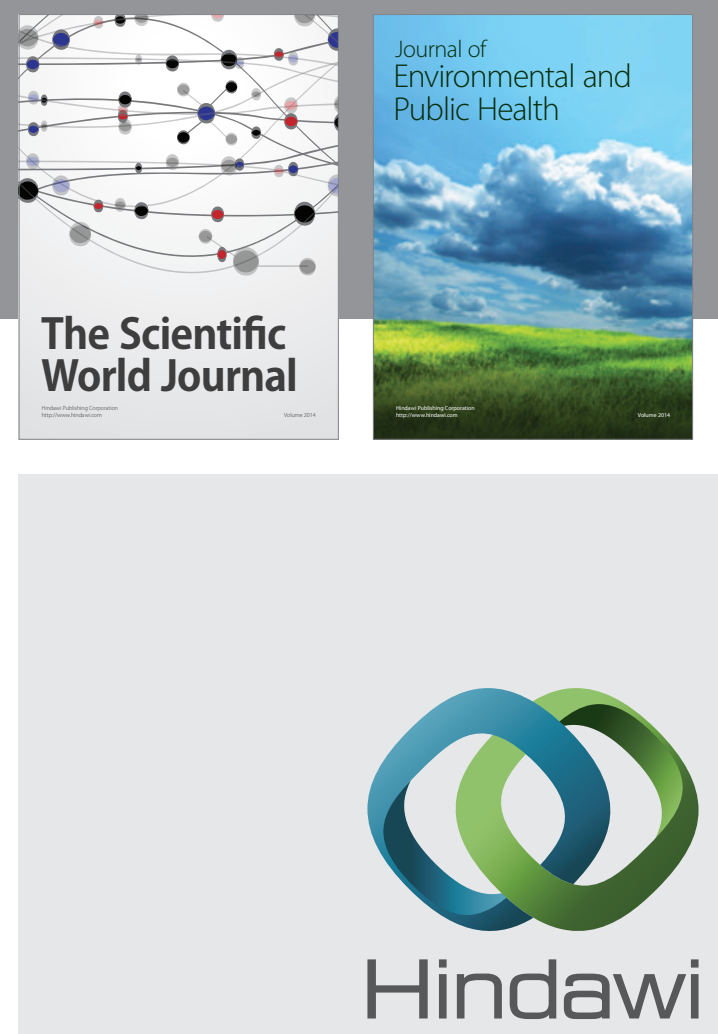

Submit your manuscripts at

http://www.hindawi.com
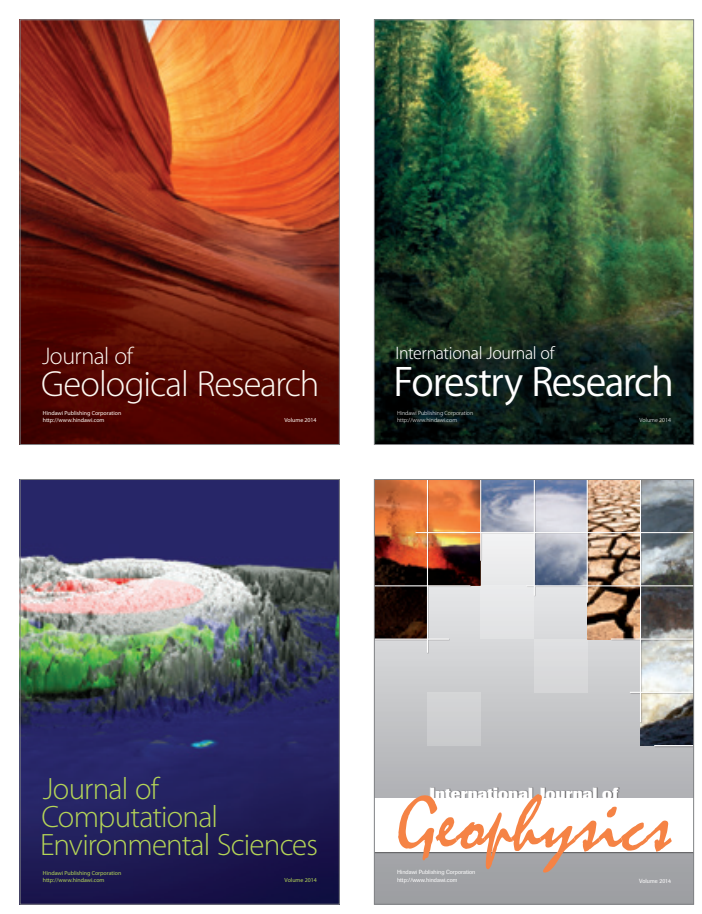
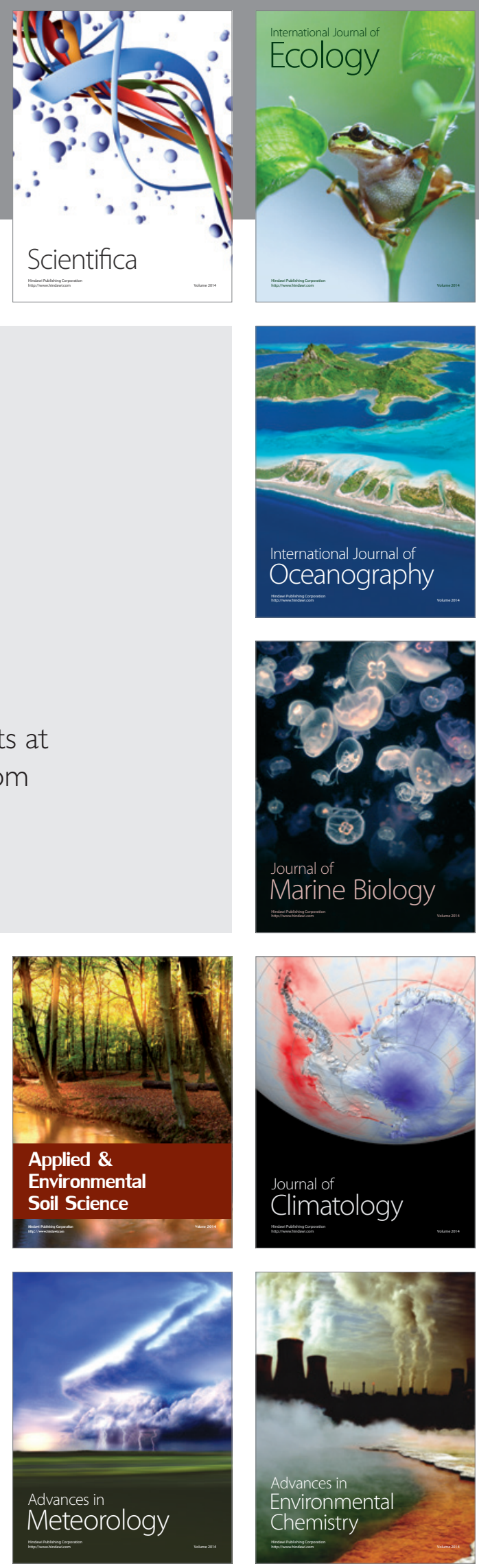